\begin{tabular}{|c|c|}
\hline Title & A spatial analysis on the determinants of tourism performance in Japanese Prefectures \\
\hline Author(s) & Romão, João; Saito, Hisamitsu \\
\hline Citation & $\begin{array}{l}\text { A siaPacific Journal of Regional Science, 1(1), } 243-264 \\
\text { https://doi.org/10.1007//41685-017-0038-0 }\end{array}$ \\
\hline Issue Date & 2017-04 \\
\hline Doc URL & http:/hdl.handle.net/2115/68668 \\
\hline Rights & $\begin{array}{l}\text { This is a post-peer-review, pre copyedit version of an article published in A sia Pacific Journal of Regional Science. The } \\
\text { final authenticated version is available onl ine at: } h \mathrm{tttp} / / / \mathrm{dx} \text {.doi.org/10.1007/\$41685-017-0038-0 }\end{array}$ \\
\hline Tyре & article (author version) \\
\hline File Information & romao_apj rs2.pdf \\
\hline
\end{tabular}

Instructions for use 


\title{
A spatial analysis on the determinants of tourism performance in Japanese Prefecture
}

\author{
João Romão \\ Centre for Advanced Studies in Management and Economics (CEFAGE - UE) \\ Hisamitsu Saito \\ Graduate School of Economics and Business Administration, Hokkaido University
}

\begin{abstract}
Assuming tourism as a place oriented activity where tourist flows often cross regional borders, local and global indicators of spatial autocorrelation can be useful tools in order to identify and to explain different patterns of regional tourism dynamics and their determinants. These techniques recently became widely used in applied economic studies, as a result of their useful insights to understand spatial phenomena and benefiting from the existence of geo-referenced data and adequate software tools. This tendency is also observed in the tourism sector in the last few years. In this work, an exploratory spatial analysis and a spatial econometric model are applied to the case of Japanese Prefectures, leading to the identification of the specific spatial aspects prevailing in Japanese regional tourism dynamics. Spatial heterogeneity and agglomeration processes are identified, with a view on policy and managerial recommendations, offering a contribution to explore potential synergies arising from inter-regional cooperation in crucial aspects of tourism development. The results reveal the existence of such spatial effects, reflecting the importance for tourism of central areas of Japan, while revealing that competition effects among Japanese Prefectures prevail over positive regional spinoffs identified in other countries. It was also possible to observe that regions where tourism plays a more prominent role in terms of its importance within regional employment do not present a relatively high performance in terms of economic impact and benefits. The results suggest that a more balanced regional economic structure and higher levels of education of the work force contribute for improvements in tourism value added. Finally, the important role of foreign tourism boosting regional tourism performance is revealed.
\end{abstract}

\section{Keywords:}

Tourism performance; Spatial Econometrics; Regional analysis; Specialization. JEL Classification: C31; R10; L83

This file corresponds to the manuscript accepted for publication as:

Romão, J., Saito, H. (2017)

A spatial econometric analysis on the determinants of tourism performance in Japanese Prefectures. Asia-Pacific Journal of Regional Science, 1(1): 243-264

doi:10.1007/s41685-017-0038-0 


\section{Introduction}

Tourism attractiveness relies on a wide range of resources available in each destination. Apart from the "traditional" tourism services (transport, accommodation, food), other aspects like the existence of natural resources and cultural amenities or the interaction with local communities clearly influence the preferences of tourists. In the case of Japan, a broad diversity of territorial characteristics constitute potential tourism attractions, both at national and international levels: the lively urban atmosphere of some metropolitan areas, the material cultural heritage expressed in a large number of monuments and a rich history, immaterial cultural aspects related to historical events and festivities or traditional ways of living, natural aspects related to particular ecosystems and landscapes, the traditional bath practices in hot springs (onsen), the appreciation of the cherry blossoms (sakura) in different parts of the country, along a rich and varied world famous gastronomy, the traditional Japanese accommodation facilities (ryokan) or the opportunities for shopping. These assets can be found - in different quantities and combinations - along the country, attracting tourists with different characteristics and motivations.

All these different aspects contributing for the touristic experience reveal the close interconnection between tourism activities, territorial resources and the overall regional socio-economic structure, which contributes for the supply of a diversified package of products and services for diverse types of tourists. Consequently, the regional economy also benefits from tourism demand and the creation of jobs in the destination areas. Contemporary tourism is highly dependent on information and digital services, which contribute to provide adequate information for the visitor, increasing interaction between service users and suppliers and, in a broad sense, for the co-creation of tourism experiences, arising from the match between the needs and requirements of tourists and the characteristics of the services available. Thus, innovative services requiring highly qualified labor are increasingly required for the development of more sophisticated services. It must be also noticed that tourism flows often cross regional borders and tourists primarily visiting one region can also visit other places around their main destination, implying that the attractiveness of a place can also depend on the resources and dynamics registered in the neighborhood. These interactions between tourism destinations have important implications in terms of resource management, mobility or destination promotion, which should be addressed at policy or managerial levels.

The purpose of this study is to analyze how different aspects of tourism demand (volume, length of stay and share of foreigners) and territorial characteristics (level of specialization in tourism and qualifications of the work force) exert some influence of the economic performance of tourism activities in Japanese Prefectures, with a particular focus on the spatial effects and interactions eventually occurring between them. For these purposes, 46 prefectures (represented in the map in Annex 1) are considered (Okinawa could not be included due to lack of some data). As the data for tourism activities is not abundant in Japan (only in 2012 the Japanese Tourism Agency started to collect information with harmonized criteria at Prefectural level), this study (based on information from 2010 presented in Annex 2) is an exploratory work, based on a limited number of variables.

Tourism activities are grouped in a sector including typical tourism services (like leisure services, accommodation and restaurants), but also other personal services, like cleaning. Despite this problem, the data seem to provide relevant results. Although the territorial level considered (Prefecture) does not correspond to a tourism destination (Prefectures normally include several different destinations), it allows us to address some relevant policy issues regarding territorial governance for tourism and regional development, as it corresponds to a strategic level of decision making (the Prefectural governments). As it will be discussed, the interactions and complementarities between regions can be important tools for tourism development and to generate socio-economic benefits for the local communities, mostly in regions where tourism is not a prominent activity. In that sense, this original approach to the spatial dynamics of tourism in Japan can offer new insights with relevant policy and managerial implications.

Taking these aspects into consideration, spatial analysis and spatial econometric models can be useful tools in order to identify and to explain different patterns of regional tourism dynamics and their 
determinants. As these interactions clearly depend on the conditions and characteristics of each place, such spatial effects can not be generalized from one study in a specific location to a different place with different characteristics. Thus, the aim of this work is to offer an original positive contribution for the analysis of the determinants of tourism performance at the Prefectural level in Japan, by using established methodologies and techniques related to spatial econometric analysis, still lacking empirical application and validation in tourism studies (in particular for the Japanese case). Benefiting from the growing availability of geo-referenced data and user-friendly computation tools, these techniques show higher importance in economic and spatial analysis in the last few years, also with relevant utilizations in the applied field of tourism.

The conceptual framework and literature review for this work will be described in the following Section, by synthetizing relevant theoretical contributions for the analysis and measurement of tourism performance and its determinants, complemented by the concrete examples of the application of spatial econometric techniques and methodologies for similar purposes. Next, the methodology will be presented, in two different levels: an exploratory spatial analysis (testing the existence of spatial effects by using Global and Local Indicators of Spatial Autocorrelation, with the introduction of spatially lagged variables), followed by a regression model, identifying general tendencies underlying the relations between the variables considered and measuring potential spatial patterns. Finally, the results will be discussed taking into considerations previous studies about spatial effects in tourism dynamics and some final concluding remarks oriented to policy implications will be offered.

\section{Literature review}

Some characteristics of the provision of tourism services enhance the close connection between tourism and territory: co-terminality (direct interaction between producer and consumer), spatiality and temporality (consumption and production of tourism services occur in the same place at the same time) distinguish tourism from other economic activities. The notion of tourism destination as an amalgam of different products and services for a multi-segmented market, with a large number of (groups of) consumers, with different needs and motivations, is clearly expressed by Buhalis (2000) or Romão et al. (2015a). Vanhove (2005) or Wall and Mathieson (2006) provide comprehensive analyses of the systemic character of tourism activities at destination level.

Following a similar comprehensive approach, Crouch and Richie (2003) state that "what makes a tourism destination truly competitive is its ability to increase tourism expenditure, to increasingly attract visitors, while providing them with satisfying, memorable experiences, and to do so in a profitable way, while enhancing the well-being of destination residents and preserving the natural capital of the destination for future generations". This definition of competitiveness includes the concepts of growth, economic impacts and benefits for the host community, along with the preservation of resources over time and consumer satisfaction, stressing the systemic character of tourism destinations and applying it to the analysis of their competitiveness.

Over the last 20 years, competitiveness in tourism has been analyzed in a large number of studies, with different formulations and indicators (Kozak 1999; Hassan 2000; Dwyer and Chulwon 2003; Enright and Newton 2004; Mazanek et al. 2007; Navickas and Malakauskaite 2009; Tsai et al. 2009). Nevertheless, comparative studies have mostly focused on the national level, being relatively scarce the comparative analyses between regions. Some examples are applied to Southern Italian regions (Cracolici and Nijkamp 2008), focusing on tourist satisfaction as the key variable to measure competitiveness, or in Spanish regions (Camisón and Forés 2015), analyzing the impact of regional economic competitiveness on the performance of tourism companies.

The analysis of the regional touristic performance in Japanese Prefectures proposed in our work assumes the gross value added per habitant of the tourism sector in each of them as the dependent variable in the regression model to be presented (as a proxy for the contribution for the economic performance of tourism services and their impacts on the well being of the hosting communities). 
Thus, our study can be broadly framed within the analysis of tourism competitiveness developed in the last decades, by focusing on its regional economic impact and potential benefits for the residents.

As a place-oriented activity (see e.g. Williams and Shaw 2011; Brouder and Eriksson 2013), tourism has a high potential for the development of practice and place-based innovation strategies, as expressed by the European Commission (2006) or Hjalager (2010), aiming at the integration into products and services of the unique and distinctive territorial characteristics that contribute to distinguish each destination from each other, in the context of a global competition for the attraction of tourists (see e.g. Hall and Williams 2008; Malakauskaite and Navickas 2010). The development of information and communication technologies in the last decades transformed the tourism sector, enhancing the interoperability and interactivity between producers and users of tourism products and services (Wang et al. 2001; Buhalis and Law 2008; Romão et al. 2015b).

In this sense, the levels of regional specialization in tourism (and the related knowledge spillovers arising from the interaction between companies or between suppliers and consumers) or the existence of highly qualified labor force can improve the conditions for the development of innovative products and services, with higher value added (Martin 2014; Boes et al. 2016). Thus, these characteristics of the territorial capital (Capello et al. 2011) of Japanese Prefectures will be included in the econometric model to be developed, in order to assess the potential impacts of innovation on the value added of tourism activities. These aspects are not usually considered in studies on tourism destination performance and, due to the availability of data, only in a larger territorial scale (like the Prefectural level assumed in this study) they can be observed and integrated into a broader perspective of regional development. Once the Prefecture corresponds to a relevant territorial level for the implementation of regional development policies, integrating the links between different sectors with innovation policies, policy implications can be extracted and discussed.

Taking into consideration the close link between tourism and the territory and the potential regional interactions arising from tourism activities, spatial analysis and spatial econometric models can be useful tools in order to identify and to explain different patterns of regional tourism dynamics and their determinants. These techniques recently became widely used in applied economic studies, as a result of their useful insights to understand spatial phenomena and benefiting from the existence of geo-referenced data and adequate software tools. This tendency is also observed in tourism mostly in the last 10 years, although the application of these methodologies is still relatively scarce.

Examples of application of exploratory spatial analysis methods based on local indicators of spatial autocorrelation were offered by Zhang et al. (2011), studying the spatial distribution of tourism flows in Chinese cities; Kang et al. (2014), focusing on large South Korean regions (a territorial level similar to what is used in our study); or Majewska (2015), analyzing NUTS 4 regions (the smallest scale within the European classification defined by Eurostat, corresponding to the municipality level) in Poland. All these authors identified patterns of spatial heterogeneity among the territories under observation, with a concentration of tourism activities within clusters of regions, not equally distributed along the national territories.

Most of the recent examples of application of spatial econometric methods for regression analysis in tourism studies focus on territorial approaches similar to the Prefectural level assumed in our study. Generally, the econometric results presented reveal the existence of positive spillover effects, suggesting that tourism development in one region tends to benefit from the dynamics observed in the neighborhood. Such positive effects were observed by Kang et al. (2014), analyzing the regional impacts of the national tourism policies in South Korean regions, or Paci and Marrocu (2014), when estimating the impacts of tourism on regional growth in 179 European regions (NUTS 2 level).

Nevertheless, Mata and Llano-Verduras (2012) observed variations over time for these spillover effects when observing tourism flows in Spanish (NUTS 2) regions; Ma et al. (2014) verified that those positive effects are different when observing the impacts of domestic and inbound tourism on urban growth in Chinese Prefectural cities; also analyzing Chinese Prefectural cities, Yang and Wong 
(2012) and Yang and Fik (2014) identified different magnitudes for the spillover effects according to the origin (national or foreign) of the visitors and also according to the destination regions. These results suggest that, although tourism activities generally exert positive impacts on the neighbor regions, the magnitude of these effects depends on the specific characteristics of each place and the type of tourism developed. The differences observed among the spatial effects identified in diverse studies for different territories also justify the need to analyze the specific characteristics of the spatial patterns of tourism development in different areas, as they are extremely sensitive to the local conditions and not possible to generalize from one place to another.

It is also important to notice that, still observing that positive spillover effects tend to prevail in most of the analysis performed, also some negative effects, related to different resource endowments or competition between regions, could be observed. Patuelli et al. (2013) focused on the relation between the existence of UNESCO classified sites and tourism growth in Italian regions (NUTS 2, according to the Eurostat definition, corresponding to the Prefectural level in Japan), identifying positive spatial impacts for the sites located in each region, but a negative spatial impact arising from the sites located in neighbor regions, suggesting the existence of important competition effects. More generally, Liu et al. (2017), analyzing a large number of Chinese cities, observed that the urban tourism dynamics is negatively affected by the abundance of tourism resources in the neighborhood. These results confirm the importance of analyzing the specific situation of each territory in order to test and to identify the possible existence, magnitude and direction of the spatial spillovers generated by tourism activities.

The importance of these spatial interaction among clusters of regions for the promotion of tourism development, generally observed in most of the studies devoted to this question, is clearly emphasized by Yang and Wong (2012), who systematize the main sources of these spillovers: the productivity aspects (related to the movement of specialized labor, demonstration effects related to good practices, or competition effects) and the market access factors (joint promotional initiatives, reaction to negative events, or the existence of tourists with multi-destination travel plans). These authors stress that, mostly for smaller regions with less developed tourism structures and more limited financial resources, inter-regional cooperation among clusters of regions can be a powerful tool in order to overcome the individual limitations and to maximize the potential benefits of tourism dynamics for regional development.

Other applications of spatial econometric methods have been used to analyze smaller territories, more close to the concept of tourism destination but less appropriate in terms of the integration of tourism performance in the broader context of regional innovation and socio-economic development policies, as it is the purpose of the current work. Marrocu and Paci (2013) used an augmented gravity model including spatial variables to analyze tourism flows between NUTS 3 regions (provinces) in Italy. In a smaller scale (municipal level, in Italy), Capone and Boix (2008) analyzed the spatial dynamics related to the sources of tourism competitiveness, while Lazzereti and Capone (2009) focused on labor markets in the tourism sector. Also focused on the labor market spatial dynamics, Chhetri et al. (2008) modeled the spatial drivers of tourism employment within a specific Australian region. Finally, at the city level, Lee and Jang (2013) analyzed the effects of location on the prices of hotel accommodation in Houston (USA). It is noteworthy to mention that all these studies identified positive spillover effects related to tourism dynamics, labor movements or prices. For the case of Japan, this type of analysis, more focused on the destination, could be seen as complimentary to the present study and it can be an interesting object of further research.

\section{Data and Methodology}

The data used for this study are presented in Annex 2. The values for the regional Gross Value Added in the tourism sector (GDPTPC) have been divided by the number of habitants in each region, reducing the variability of the data and increasing the reliability of the estimations. The same has been done regarding the number of college graduates in the region (EDUC), a proxy for the qualifications of the labor force. The other variables directly related to tourism taken into consideration are the share of tourism within the regional Gross Domestic Product (GDPTS) and the regional employment 
(EMPTS), measuring the regional specialization in tourism; the nights spent in accommodation establishments (also per capita) (N), the share of foreigners within the nights spent in accommodation (NFS) and the length of stay of tourists (LS), reveal the regional tourism demand characteristics. The source of information for population, college graduates, employment, and employment in tourism was the "2010 Population Census", by the Statistics Bureau of Japan (2011). Data for GDP and GDP in tourism was collected in the "Annual Report on Prefectural Accounts", published by the Cabinet Office of the Government of Japan (2011). Finally, the number of overnight stays (total and foreigners) and the number of visitors were found at the "Accommodation Survey" by the Japan Tourism Agency (2011).

This section includes an exploratory spatial analysis (Section 3.1) and a regression model (Section 3.2). The exploratory spatial analysis includes a univariate analysis (for each of the variables in the present study), in order to understand how the regional tourism performance is linked to the dynamics observed in the surrounding areas. Next, a spatial econometric regression is conducted, providing the identification and quantification of the overall impacts of the explanatory variables on the regional performance of tourism activities in Japanese Prefectures, also allowing for the estimation of spatial effects among them.

\subsection{Exploratory Spatial Analysis}

A Local Indicator of Spatial Autocorrelation (LISA) is a statistic that gives, for each observation, an indication of the extent of significant spatial clustering of similar values around that observation (Anselin, 1995). The sum of the LISAs for all observations should be proportional to a Global Indicator of Spatial Autocorrelation. In this case, the Moran-I statistic will be used, given by the following expression:

$\mathrm{I}=\mathrm{z}_{\mathrm{i}} \sum_{\mathrm{j}} \mathrm{W}_{\mathrm{ij}} \mathrm{z}_{\mathrm{j}}$

where:

$\mathrm{z}_{\mathrm{i}}$ is the original variable $\mathrm{x}_{\mathrm{i}}$ in "standardized form" or in "deviation form";

$\mathrm{w}_{\mathrm{ij}}$ is the spatial weight.

The "spatial weight" measures the impact of a region in each other (see e.g. Vega and Elhorst 2013; Elhorst 2014). Normally, it is assumed that this impact tends to decay with distance. There are several methods to define this proximity (geographic contiguity or geographical distance, but also other types of indicators, like the intensity of trade between regions). In this case, taking into consideration that tourism activities can spread among regions geographically close, a measure based on geographical distance is used. As the territory of Japan includes some Prefectures with a small number of adjacent units (like Kochi, Kagawa, Aomori or Nagasaki) or even without any adjacent unit (Hokkaido), the contiguity criterion would raise estimation problems, as some regions would have a very limited number of neighbors (or even no neighbor at all). In the case of tourism, this question has been observed by Yang and Wong (2012) for their analysis of Chinese Prefectural cities, implying the option for another type of measure for geographical proximity.

Following the methodologies adopted in other spatial analysis devoted to tourism dynamics with similar territorial level (e.g. Patuelli et al. 2013; Yang and Fik 2014; or Yang and Wong 2012), the neighborhood is defined taking into consideration the 5 closest neighbors for each region, considering the geographical (Euclidean) distance between the centroids of each Prefecture (as it will be seen in the next Sub-section, an alternative specification has also been implemented, with very similar results). With this information, a spatial weight matrix is defined, identifying which regions impact others. Although the regional spillover effects tend to be very sensitive to the regional characteristics, type of tourism activities developed and focus of the analysis, the adoption of this methodology has lead to significant results, with relevant policy implications. 
In this case, the Moran-I statistic will be used, including a Global Indicator of Spatial Autocorrelation (GISA) for each variable. The statistical relevance of the scores obtained for the GISA can be compared with a random spatial distribution, generated through a process of permutations $(99$, in this case). Based on this process, a z-score can be obtained, allowing to infer the statistical relevance of the spatial effects identified. In this work, a significance level of $5 \%$ will be taken into account, implying that spatial effects will be considered relevant when the z-scores obtained for GISA based on the Moran's I statistic are above 1.96 (a detailed explanation on these calculations is provided by Anselin $1995 ; 2005)$.

It is important to notice that the clusters identified in the map of the right hand side are represented only by its center, which means that the cluster also includes the 5 neighbor regions. These clusters occur when the value obtained for the non-lagged variable is more similar (positive autocorrelation) or dissimilar (negative autocorrelation) to the value of the lagged variable (the weighted average of the neighboring values) than it would be in case of spatial randomness. They are represented by dark colors when a positive autocorrelation is identified (red when high values for one region and its neighbors are identified and blue for low values for a region and its neighbors). Light colors are used to represent negative autocorrelation (blue for low values in a region surrounded by regions with high scores and red for the inverse situation). Regions with no color do not reveal statistically significant levels of spatial autocorrelation.

For each variable, when the GISA is statistically relevant, a Figure will show 3 components: a map on the left hand side, with the distribution of the values observed for that variable (based on quintiles, with a similar number of observations in each class and darker colors representing higher values); a box-plot in the center, representing in a column the scores for the different regions, allowing to identify "outliers" (extreme values, observed when the score for one region is above or below the average plus or minus the standard deviation multiplied by 1.5); and a cluster map on the right hand side, representing the type of local spatial autocorrelation identified for the regions where this was statistically relevant.

The first variable analyzed in this section is the gross value added created in the tourism sector (Figure 1). In this case, the Moran's I statistic has a score of 0.191 (pseudo value of 0.0100 ), with a corresponding z-value of 2.854, clearly above the threshold of 1.96 and suggesting the existence of global spatial effects. The map on the left reveals a concentration of high-values in the central region of Japan, while the box-plot shows the Prefecture of Tokyo as a positive outlier ( 0.43 million yen per habitant, while Kyoto and Osaka - the next in the rank - only achieve around 0.27 million). The local indicators of spatial autocorrelation in the map on the right hand side reveal clusters of low scores around the Prefectures of Shimane, Hiroshima, Yamaguchi and all the Northern regions, while high values concentrate mostly around Ibaraki, Chiba and Yamanashi. Relatively low scores surrounded by high values were identified around the Prefectures of Gumma, Saitama and Shizuoka. These results are clearly in accordance with previous studies (e.g., Kang et al., 2009; Majewska, 2015), revealing the spatial heterogeneity of the distribution of tourism activities, which tend to concentrate in some clusters of regions.

Figure 1: Regional GDP per capita in the tourism sector

A different situation occurs when the share of foreigners within the overnights spent in accommodation establishments is taken into account (Figure 2). In this case, the score for the Moran I statistic (0.143, with a pseudo p-value of 0.0400 and a $\mathrm{z}$-value of 2.271) is also high, clearly suggesting the existence of spatial effects. High scores clusters around the Prefectures of Yamanashi and Kanagawa, while low scores occur in Akita, Iwate, Yamagata, Miyagi, Nigata and Fukushima. Gumma, Saitama, Shizuoka and Nara are regions where a lower proportion of foreign tourists is related to relatively high scores in the neighborhood, while the contrary is observed in Hokkaido. The box-plot reveals that Chiba, Yamanashi and Kyoto (more than 10\% of foreigners), Osaka (15\%) and Tokyo $(20 \%)$ are clearly above the national average. This information shows that foreign tourists tend 
to concentrate in specific clusters of regions, which will have important policy implications (as discussed later on).

Figure 2: Share of foreigners in the nights spent in accommodation establishments

The levels of the qualification of the regional population (represented in Figure 3) are generally assumed to have a positive impact on the regional economic dynamics, the innovation capabilities or the quality of the services. In this case, the number of persons achieving the graduate level of education (as a proportion of the total population) is assumed as a proxy for the qualification of the labor force in each region. In this case, the score for the Moran's I statistic $(0.493$, with pseudo pvalue of 0.0100 and z-value of 5.2471) reveals the existence of spatial effects. In fact, the map on the left clearly reveals higher scores in the center of Japan and lower scores in the peripheral areas, while the box-plot shows that Tokyo, Kanagawa (both around 20\%) and Nara (with 18\% of graduates within the regional population) are much above the national average for this indicator. The map on the right hand confirms this idea, with clusters of high values in Saitama, Chiba, Yamanashi, Tokyo, Kanagawa, Shizuoka, Osaka and Kyoto, while low scores concentrate around the Prefectures of North (Hokkaido, Aomori, Akita, Iwate, Yamagata and Miyagi) and South of Japan (Saga, Kumamoto and Kagoshima).

Figure 3: Qualifications (share of college graduates in the regional population)

Some remarks can be made regarding the variables that did not show statistically relevant global indicators of spatial autocorrelation. When analyzing the regional specialization in tourism activities, measured by the share of tourism in the regional GDP, it was observed that the Prefecture of Nara (with $9.3 \%$ of its GDP generated by the tourism sector) is clearly above all the other regions, while measuring specialization according to the importance of employment in the tourism sector very similar scores were registered along the country, with relatively low deviations regarding the average: higher score for Yamanashi (more than 11\% of the work force employed in tourism) and lower scores for Okayama and Tokushima (less than 8.5). Regarding tourism demand (number of overnight stays per habitant), some degree of concentration is observed in the central regions of Japan, with Yamanashi (a Prefecture with relatively low population, where some major tourism attractions - like the Mount Fuji and the Five Lakes - are located) being the only Prefecture clearly above the average (almost 6 nights spent by tourists).

\subsection{A spatial econometric model}

The exploratory spatial analysis conducted is now complemented by a regression, aiming to provide an overall explanation for the relations previously identified and to quantify the (potentially) existing spatial effects. A panel data model (including several time periods of observations for each variable) would surely provide more accurate and interesting results than a single observation, but it is still not possible to obtain some relevant information. Nevertheless, this is an interesting potential development of this work, to be addressed in further research.

The dependent variable in the model to be estimated is the regional gross domestic product per habitant in the tourism sector (GDPT), while all the variables included in the spatial analysis previously conducted will be considered as explanatory variables. Nevertheless, some of them revealed problems of multicollinearity or leaded to the estimation of parameters with very low statistical significance. After eliminating those variables, the results for the estimation of a regression not including spatial effects are presented in Table 1.

As it can be seen, four explanatory variables remained: level of qualifications of the work force (EDUC), specialization in tourism, measured by the share of tourism within the regional GDP (GDPTS), share of foreigners within the regional overnight stays (NFS) and nights spent in regional accommodation establishments per habitant (NPC). The estimation was computed with GeodaSpace 1.0 for MacOS, based on the ordinary least squares (OLS) method. 
As it could be expected, it is possible to observe that all these variables have a positive impact on the regional gross value added by the tourism sector, although, for the proxy of tourism demand (nights spent in accommodation establishments), the statistical significance is still relatively low. On the other hand, it is also relevant to notice that aspects like the length of stay of tourists or the share of tourism within the regional employment do not have a statistically significant correlation with the regional gross value added in tourism.

Table 1: Estimations for OLS regression without spatial effects

The results of the model (with an Adjusted R-squared of 0.64) revealed the absence of multicollinearity problems (the multicollinearity condition number [see e.g. Belsley et al. 1980] scored 22.673, before the critical threshold of 30), while the Jarque-Bera test for the normality of errors (Jarque and Bera 1980) scored 29.682 (with 2 degrees of freedom), leading to the rejection of the null hypothesis of normal distribution of errors and opening the possibility for the existence of spatial effects within the distribution of the error terms. Finally, the diagnostic tests for heteroskedasticity suggest the presence of heteroskedasticy, which should be taken into account in the computation of a spatial regression model: the Breusch-Pagan test scored 71.370 with 4 degrees of freedom (Breusch and Pagan 1979); the Koenker-Bassett test scored 27.468 with 4 degrees of freedom (Koenker and Bassett 1982); and the White test scored 39.762, with 14 degrees of freedom (White 1980).

As mentioned before, the computation of a spatial regression model requires the definition of a weights matrix, defining the impact of one region on each other. In this work, two matrixes have been computed in order to check the stability of the results: as mentioned before, one matrix was based on the five closest neighbors for each region (Regression 1) and the other matrix was based on the geographical distance between the centroids of each region, considering as neighbors all the Prefectures included within a threshold distance, automatically defined so as to ensure that all the Prefectures have at least one neighbor (Regression 2). The results for the models based on these two matrixes are presented in Table 2 and it is possible to observe that the estimations for the different parameters are extremely similar, suggesting that the results obtained are not highly dependent on the methodology adopted to define the weights matrix. As the statistical significance for the spatial error effects was higher when using the matrix based on the 5 closest neighbors, the following results (and also the previous exploratory spatial analysis) relate to the utilization of this matrix.

Several tests for the existence of spatial effects within the dependent variable (spatial lag) or among the distribution of the error terms (spatial error) were also performed using GeodaSpace 1.0 (see e.g. Baltagi, Song and Koh 2003; 2007). The Lagrange Multiplier (LM) tests for the spatial lag (scoring 0.047 ) and the error term (scoring 1.225) both lead to the rejection of the null hypothesis (inexistence of spatial effects), once the associated probabilities were, respectively, 0.828 and 0.269 . The robust LM tests suggested the same conclusions, with scores of 1.513 (probability of 0.219 ) for the spatial lag and 2.691 (probability of 0.101 ) for the spatial error, also leading to the rejection of the null hypothesis (inexistence of spatial effects). Thus, the model to be estimated is a Cliff-Ord spatial model (Cliff and Ord 1981), including spatial error and spatial lag terms, which, in its general form, can be specified as (Lesage and Fischer 2008; Elhorst 2014):

$\mathrm{Y}_{\mathrm{it}}=\rho \mathrm{WY} \mathrm{Y}_{\mathrm{i}}+\mathrm{X}_{\mathrm{i}} \beta+\mathrm{u}_{\mathrm{i}}$

$\mathrm{u}_{\mathrm{it}}=\lambda \mathrm{Wu}_{\mathrm{i}}+\varepsilon_{\mathrm{i}}$

where:

- Y represents the dependent variable (gross domestic product in tourism per habitant, as a proxy for regional tourism performance);

- $\quad \mathrm{X}$ represents the independent variables;

- $\quad$ W is a nonnegative $\mathrm{N} \times \mathrm{N}$ matrix of known constants describing the spatial dependency impacts among regions; as explained before, each element $\mathrm{w}_{\mathrm{ij}}$ measures the intensity of the relationship between units $\mathrm{i}$ and $\mathrm{j}$; 
- WY measures the endogenous interaction effects among the dependent variable;

- $\quad \rho$ is the spatial autoregressive coefficient (measuring the spatial lag);

- $\quad \lambda$ is the spatial autocorrelation coefficient (measuring the spatial error);

- $\quad \mathrm{i}$ is an index for the regions.

The estimations of the model have also been made with GeodaSpace 1.0, by using a two steps Ordinary Least Squares method. Spatially lagged variables have been used as instruments for the dependent variable (GDPTPC) and for 3 of the independent variables (EDUC, NFS and NPC), ensuring that they are asymptotically uncorrelated with the error term. The transformations proposed by Kelejian and Prucha (2010) were also applied, in order to deal with the heteroskedasticity within the distribution of the error terns previously identified (a more detailed description of this specification can be found in Arraiz et al. 2010; or Drucker et al. 2013). Table 2 presents the results of this estimation for the parameters related to variables revealing statistical significance at $5 \%$ level (with the exception of the variable related to tourism demand - nights spent in accommodation establishments per habitant -, which is only relevant at $10 \%$ level). Regression 1 relates to a weight matrix based on the 5 closest neighbors, while regression 2 relates to a weight matrix based on the inverse distance between regions.

Table 2: Estimations for GMM regression with spatial effects

The results obtained (with spatial pseudo r-squared of 0.66 for both Regressions) confirm the relations previously identified by the model without spatial effects, with a positive correlation between the gross value added by tourism activities and the education levels, tourism demand and share of international visitors within the nights spent in accommodation establishments. Also similarly to the previous case, the statistical relevance of international tourism is much higher than the observed for the overall tourism demand, suggesting a higher importance of foreign tourism as a determinant of the regional tourism performance. The most important novelty arising from the computation of this model is the identification of relevant spatial effects, both for the dependent variable (suggesting a positive effect of tourism dynamics in one region on the performance of its neighbors) and for the error term (in this case, suggesting the existence of negative unmodelled effects).

\section{Discussion}

This analysis clearly reveals the importance of the central regions of Japan - especially those around Tokyo Metropolitan area - in terms of the GDP produced by the tourism sector. Confirming this idea, the spatial analysis conducted revealed the existence of clusters of regions with high levels for the GDP in tourism around the central areas of Ibaraki, Chiba and Yamanashi. These results are in accordance with other studies applying similar methodologies in different countries, including China (Zhang et al., 2011), Poland (Majewska, 2015) or South Korea (Kang et al., 2014), where it was observed that tourism activities tend to concentrate within clusters of regions, with a heterogeneous distribution along the countries.

In general terms, those are also the regions where foreigners assume greater importance within the overall visitors. The importance of inbound tourism for the higher achievements in terms of regional gross value added by tourism services (identified in a large number on tourism performance over the last decades) is clearly revealed by the results of the spatial econometric model computed, identifying the share of foreign tourists as one of the major determinants of tourism dynamics in each Prefecture. In fact, the importance of foreign tourism for the performance of destinations is widely documented in the literature over the last decades.

It also noteworthy that the high levels for the GDP per habitant in tourism registered in Tokyo do not have a similar correspondence in terms of tourism demand per capita (which is relatively lower), revealing that tourism products and services provided in this region have higher value added than in other regions of Japan and suggesting higher levels of productivity. In fact, despite its leadership among the Japanese Prefectures regarding the GDP of the tourism sector, Tokyo does not rank among 
the first positions when looking at the specialization in tourism, both when we consider the GDP or employment in the tourism sector within the overall regional economy.

Apart from the importance of foreign tourism, Tokyo and the central areas of Japan also tend to show higher levels of education for the work force, when compared with the peripheral areas of the country (both in the North and South of Japan), which can be seen as an important asset regarding the regional innovation capabilities. This seems to be in accordance with the recent conceptualizations proposed by several authors (e.g. Buhalis and Law 2008; Williams and Shaw, 2011; Brouder and Eriksson 2013; Martin, 2014; or Boes et al., 2016), who suggest that the ability to integrate knowledge and technology (in particular related to information and communications) can have a decisive contribution boosting the tourism performance in each destination.

On the other hand, it is also possible to observe that the Northern regions of Japan clearly reveal lower levels of GDP generated by the tourism sector, even when tourism is especially important for regional employment. One clear example is the most Northern region of Japan (Hokkaido), ranking in the first positions in terms of the share of the active population employed in tourism but revealing a much weaker position in terms of the contribution of tourism for the regional GDP. This clearly suggests that the region provides services with relatively low value added and less economic impacts on the regional economy. As it can be observed, Hokkaido is also a region with relatively low qualification of the work force in the Japanese context.

Based on the regression analysis developed in Section 4, it was possible to identify the main determinants of tourism performance (measured by the gross value added by the tourism sector per habitant) within the variables considered. It is noticeable that a high specialization in tourism is not necessarily related to a high performance of this sector, while it was also possible to identify that the length of stay is not a major determinant either. On the other hand the presence of international tourism seems to play a major role determining the regional tourism performance, along with the levels of education of the regional work force. These results have relevant policy implications, once they reveal the importance of attracting international visitors and improving the qualification of the work force. In both cases, regions where tourism is less developed have much more difficulties to implement relevant policy actions if they act in isolation.

The inclusion of spatially lagged dependent variable (gross valued by tourism per habitant) allowed for the identification of positive spatial spinoffs arising from tourism dynamics in one region on their neighbors, as it was previously identified in similar studies in China (Yang and Wong 2012; Yang and Fik 2014), South Korea (Kang et al. 2014), or European regions (Paci and Marrocu 2014). Conversely, it is also important to notice that a weak regional tourism performance also has negative impacts on the neighbor regions. In this sense - and taking into account that regions with higher tourism performance are concentrated in Central areas of Japan - these results suggest the importance of interregional cooperation, mostly in areas where tourism is less developed.

Combining the systematization proposed by Yang and Wong (2012) for the crucial aspects of interregional cooperation for tourism development with the results of our econometric model for the determinants of regional tourism performance, it is possible to suggest that this cooperation can be focused on the reinforcement of work force qualifications and the promotional activities oriented to the attraction of foreign tourists, which appears as the most relevant elements to increase the gross value added by tourism services. By exploring the multi-destination travel plans currently adopted by many tourists, this cooperation can allow regions with less resources and weaker tourism performance to achieve results that would not be possible acting in isolation.

Additionally, the existence of (unmodelled) negative spillover effects, identified through the spatial distribution of the error terms, reinforces the importance of this inter-regional cooperation, in order to mitigate or to revert them. These negative impacts can be related to competition effects between regions and they were observed in previous studies, when analyzing the impact of the abundance of tourism resources in one region on the attractiveness of its neighbor regions. Relevant examples are 
offered by Patuelli et al. (2013), focusing on the existence of UNESCO classified sites in Italian regions, or Liu et al. (2017), analyzing the spatial effects of tourism attractiveness in Chinese cities. In this sense, coordination of tourism policies among neighbor regions, both in terms of promotional activities, resource management or transportation services can potentially contribute to generate mutual benefits in order to reinforce tourism dynamics along the different regions of Japan.

\section{Conclusions}

A first conclusion of this work is the empirical validation of the utilization of spatial econometric methods in the analysis of tourism activities. As it has been described, previous studies applying similar techniques in different places and with diverse purposes have revealed different results for identification and quantification of spatial effects. In fact, even analyzing the same territory, spatial patterns and effects can vary over time, as observed by Mata and Llano-Verduras (2012) for Spanish regions, or between different groups of tourists, as noted by Yang and Wong (2012), Ma et al. (2014), or Yang and Fik (2014) in Chinese cities. These results show that the direction and magnitude of spatial spillover effects related to tourist activities can be different, according to the characteristics of the place and the specific dynamics of tourism in each moment. In this sense, our work offers an original analysis of such spatial effects in Japanese tourism, with relevant results and policy implications.

Confirming that tourism in Japan follows a heterogeneous spatial distribution, with concentration of these activities in some clusters of regions, mostly located in the central area the country, our exploratory spatial analysis revealed a relative disconnection between tourism specialization and the performance of the sector. In fact, regions where tourism plays a more prominent role in terms of the regional economy and employment are not necessarily those where the sector achieves higher levels of value added. This result suggests that a balanced regional economic structure, where other sectors reveal a positive dynamism, contribute for the achievement of better results within the tourism sector. This can be related to the development of different types of tourism (cultural or business tourism) or to the development of more sophisticated tourism services, with higher value added.

The positive correlations identified in the spatial econometric model between education levels, share of foreigners within the tourism demand and tourism demand, seem to confirm this possibility, as higher levels of education are normally related to stronger technological and innovative capabilities, leading to more sophisticate products and services. This is particularly relevant in the context of the intensification and generalization of the utilization of digital technologies in the tourism sector, potentially contributed for the development of more sophisticated products and services, with higher value added, while contributing for the creation of new jobs requiring more advanced skills and educational levels.

The econometric model computed also revealed the importance of foreign visitors for the achievement of better results for the tourism sector, emphasizing the importance of the internationalization of this activity. As it was possible to observe, this is particularly relevant for the Prefectures (like Hokkaido or Kochi) where tourism plays a more prominent socio-economic role, but does not contribute with a high value added. Thus, new forms of attracting foreign visitors and closer links with more innovative and technologically advanced sectors seem to be necessary for these regions to achieve better results in the future. On the other hand, the negative spillover effects identified for the distribution of the error terms of our spatial econometric model (competition effects) emphasize the importance of interregional coordination of tourism development policies, related to international promotion, labor qualifications, demonstration of good practices, transport policies or resource management. As it has been discussed, this is particularly important for the regions where tourism is less developed.

The combination and complementarity of the results obtained through the spatial econometric model and exploratory spatial analysis offer some relevant insights about the characteristics, potential and problems of tourism in Japanese Prefectures, emphasizing the importance of the integration of tourism within a balanced economic structure and innovative context, which are aspects that can be addressed 
at the policy level of the Prefecture. Nevertheless, other aspects related to specific characteristics of each destination (climate, amenities, culture, seasonality patterns, etc.) and how they can be integrated and promoted as tourism products and services, mostly for international markets, require a more detailed territorial analysis. In that sense, the analysis of the destination level can complement the tendencies identified in this work and constitute an important further development of this analysis. 


\section{References:}

Anselin L (1995) Local Indicators of Spatial Association - LISA. Geographical Analysis 27(2): 93 115

Arraiz I, Drukker D, Kelejian H and Proucha I (2010) A spatial Cliff-Ord-type model with heteroskedastic innovations: small and large sample results. Journal of Regional Science 50(2): 592614

Anselin, L. (2005) Exploring Spatial Data with GeoDaTM: A Workbook. Santa Barbara: Center for Spatially Integrated Social Science

Baltagi B, Song S, Jung B and Koh W (2007) Testing for Serial Correlation, Spatial Autocorrelation and Random Effects Using Panel Data. Journal of Econometrics 140(1): 5-51

Baltagi B, Song S and Koh W (2003) Testing Panel Data Regression Models with Spatial Error Correlation. Journal of Econometrics 117: 123-150

Belsley A, Edwin K and Roy E (1980) Regression Diagnostics: Identifying Influential Data and Sources of Collinearity. John Wiley and Sons, New York

Boes K, Buhalis D and Inversini A (2016) Smart tourism destinations: ecosystems for tourism destination competitiveness. International Journal of Tourism Cities 2(2): 108-124

Breusch T and Pagan A (1979) A Simple Test for Heteroskedasticity and Random Coefficient Variation. Econometrica 47(5): 1287-1294

Brouder P and Eriksson R (2013) Tourism Evolution: On the Synergies of Tourism Studies and Evolutionary Economic Geography. Annals of Tourism Research 43: 370-389

Buhalis D (2000) Marketing the competitive destination of the future. Tourism Management 21: 97116

Buhalis D and Law R (2008) Progress in information technology and tourism management: 20 years on and 10 years after the Internet - The state of eTourism research. Tourism Management 29(4): 609623

Cabinet Office of the Government of Japan (2011) Annual Report on Prefectural Accounts. Cabinet Office of the Government of Japan, Tokyo

Camisón C and Forés B (2015) Is tourism firm competitiveness driven by different internal or external specific factors? New empirical evidence from Spain. Tourism Management 48: 477-499

Capello R, Caragliu A and Nijkamp P (2011) Territorial Capital and Regional Growth: Increasing Returns in Knowledge Use. Tijdschrift voor Economische en Sociale Geografie 102(4): 385-405

Capone F and Boix R (2008) Sources of growth and competitiveness of local tourist production systems: an application to Italy (1991-2001). Annals of Regional Science 42: 209-224

Chhetri P, Corcoran J and Hall CM (2008) Modelling the Patterns and Drivers of Tourism Related Employment for South-East Queensland, Australia - A Spatial Econometric Approach. Tourism Recreation Research, 33(1): 25-38

Cliff A and Ord J (1981) Spatial Processes, Models and Applications. Pion, London. 
Cracolici M and Nijkamp P (2008) The attractiveness and competitiveness of tourist destinations: A study of Southern Italian regions. Tourism Management 30: 336-344

Crouch G and Ritchie J (2003) The competitive destination: A sustainable tourism perspective. Cabi Publishing, Australia

Drukker D, Egger P and Prucha I (2013) On two-step estimation of a spatial autoregressive model with autoregressive disturbances and endogenous regressors. Econometric Reviews 32(5-6): 686-733

Dwyer L and Chulwon K (2003) Destination Competitiveness: Determinants and Indicators. Current Issues in Tourism 6(5): 369-414.

Elhorst J (2014) Spatial Econometrics: From Cross-Sectional Data to Spatial Panels. Springer, Berlin

Enright M and Newton J (2004) Tourism destination competitiveness: a quantitative approach.

Tourism Management 25: 777-788.

European Commission (2006) Innovating in tourism: How to create a tourism learning area.

European Commission, Brussels

Hall C and Williams A (2008) Tourism and innovation. Routledge, New York

Hassan S (2000) Determinants of market competitiveness in an environmentally sustainable tourism industry. Journal of Travel Research 38(3): 239-245.

Hjalager A (2010) A review of innovation research in tourism. Tourism Management 31(1): 1-12

Japan Tourism Agency (2011) Accommodation Survey. Japan Tourism Agency, Tokyo

Jarque C and Bera A (1980) Efficient tests for normality, homoscedasticity and serial independence of regression residuals. Economics Letters 6(3): 255-259

Kang S, Kim J and Nicholls S (2014) National Tourism Policy and Spatial Patterns of Domestic Tourism in South Korea. Journal of Travel Research 53(6): 791-804

Kelejian H and Prucha I (2010) Specification and estimation of spatial autoregressive models with autoregressive and heteroskedastic disturbances. Journal of Econometrics 157: 53-67

Koenker R and Bassett G (1982) Robust Tests for Heteroscedasticity Based on Regression Quantiles. Econometrica 50(1): 43-61

Kozak M (1999) Destination Competitiveness Measurement: Analysis of Effective Factors and Indicators. European Regional Science Association Conference Papers, Dublin.

Lazzeretti L and Capone F (2009) Spatial Spillovers and Employment Dynamics in Local Tourist Systems in Italy (1991-2001). European Planning Studies 17(11): 1665-1683

Lee SK and Jang S (2013) Asymmetry of Price Competition in the Lodging Market. Journal of Travel Research 52(1): 56-67

Lesage J and Fischer M (2008) Spatial Growth Regressions: Model Specification, Estimation and Interpretation. Spatial Economic Analysis 3(3): 275-304 
Liu J, Nijkamp P, Huang X and Lin D (2017) Urban livability and tourism development in China: Analysis of sustainable development by means of spatial panel data. Habitat International. In press

Ma T, Hong T and Zhang H (2015) Tourism spatial spillover effects and urban economic growth. Journal of Business Research 68(1): 74-80

Majewska J (2015) Inter-regional agglomeration effects in tourism in Poland. Tourism Geographies 17(3): 408-436

Malakauskaite A and Navickas V (2010) Level of clusterization and tourism sector competitiveness. Engineering Economics 21(1): 60-67

Marrocu E and Paci R (2013) Different tourists to different destinations - Evidence from spatial interaction models. Tourism Management 39: 71-83

Martin R (2014) Path dependence and the spatial economy. In Fischer M and Nijkamp P (Eds) Handbook of Regional Science, pp. 609-629. Springer, New York.

Mata T and Llano-Verduras C (2012) Spatial pattern and domestic tourism: An econometric analysis using inter-regional monetary flows by type of journey. Papers in Regional Science 91(2): 437-470

Mazanek J, Wober K and Zins A (2007) Tourism Destination Competitiveness: From Definition to Explanation?. Journal of Travel Research 46: 86-95.

Paci R and Marrocu E (2014) Tourism and regional growth in Europe. Papers in Regional Science 93 Supplement 1: S26-S50

Patuelli R, Mussoni M and Candela G (2013) The effects of World Heritage Sites on domestic tourism: a spatial interaction model for Italy. Journal of Geographical Systems 15: 369-402

Romão J, Neuts B, Nijkamp P, van Leeuwen ES (2015a) Urban Tourist Complexes as Multi-Product Companies: Culture, Product Differentiation and Market Segmentation in Amsterdam. Tourism Economics 21(3): 455-474

Romão, J., Neuts, B., Nijkamp, P., Leeuwen, E.S. van (2015b) Tourist Loyalty and e-Services: A Comparison of Behavioural Impacts in Leipzig and Amsterdam, Journal of Urban Technology, 22, 2: $85-101$

Ritchie J and Crouch G (2003) The competitive destination: A sustainable tourism perspective. CABI International, Oxfordshire

Statistics Bureau of Japan (2011) 2010 Population Census. Statistics Bureau of Japan, Tokyo

Tsai H, Song H and Wong K (2009) Tourism and Hotel Competitiveness. Journal of Travel and Tourism Marketing 26(5): 522-546.

Vanhove D (2005) The economics of tourism destinations. Elsevier, Oxford.

Vega S and Elhorst J (2013) On spatial econometric models, spillover effects, and W. ERSA conference papers, ersa13p222. Wien

Wall G and Mathieson A (2006) Tourism: change, impacts and opportunities. Pearson Educational Ltd, Essex 
Wang Y, Yu Q and Fesenmaier D (2001) Defining the virtual tourist community: Implications for tourism marketing, Tourism Management 23(4): 407-417

White H (1980) A Heteroskedasticity - Consistent Covariance Matrix Estimator and a Direct Test for Heteroskedasticity. Econometrica 48(4): 817-838

Williams A and Shaw G (2011) Internationalization and innovation in tourism. Annals of Tourism Research 38: 27-51.

Yang Y and Fik T (2014) Spatial effects in regional tourism growth. Annals of Tourism Research 46: 144-162

Yang Y and Wong KKF (2012) A Spatial Econometric Approach to Model Spillover Effects in Tourism Flows. Journal of Travel Research 51(6): 768-778

Zhang Y, Xu J and Zhuang P (2011) The Spatial Relationship of Tourist Distribution in Chinese Cities. Tourism Geographies 13(1): 75-90 